\title{
Religião no noticiário: marcas de um imaginário exclusivista no jornalismo brasileiro
}

\section{Magali Nascimento Cunha}

\section{Resumo}

Este texto tem o objetivo de avaliar a forma como os diferentes grupos religiosos estão representados em matérias de mídias noticiosas do Brasil e a compreensão de religião construída e afirmada pelos produtores dessas notícias. 0 estudo foi guiado pela hipótese de que o noticiário enfatiza 0 catolicismo romano institucionalizado, alimentado pelo imaginário social de "verdadeira e válida religião". Por meio de uma análise de conteúdo, foi possível identificar, a partir de um levantamento das matérias que trataram do tema "religião", durante 0 ano de 2014, no acervo da Folha de S. Paulo e do Jornal Nacional, como uma noção exclusivista de religião é construída no país a partir do noticiário.

\section{Palavras-Chave}

Noticiário. Religião. Imaginário.

\section{Magali Nascimento Cunha}

I magali.cunha@metodista.br

Professora do Programa de Pós-Graduação em Comunicação Social da Universidade Metodista de São Paulo - UMESP, Brasil.
Como as mídias noticiosas cobrem a religião no Brasil? Qual é a noção de religião no país construída por jornalistas nas matérias sobre religião que produzem? Este texto foi orientado por estas duas questões com o objetivo de avaliar a forma como os diferentes grupos religiosos estão representados em matérias de mídias noticiosas do Brasil e qual é a compreensão de religião que é construída e afirmada pelos produtores dessas notícias. 0 estudo foi guiado pela observação preliminar de que o noticiário cobre primordialmente 0 cristianismo, com ênfase no catolicismo romano institucionalizado. Deriva daí a hipótese de que este processo de construção das notícias resulta de um processo cultural hegemônico alimentado pelo imaginário social de "verdadeira e válida religião", atribuído ao catolicismo romano, o qual permeia a visão de mundo de quem produz o material noticioso.

Para desenvolver a pesquisa, com base em fontes bibliográficas que embasam estudos referentes à religião no país e ao processo de construção da notícia, foi realizado um levantamento das matérias que trataram do tema "religião", a partir 
da busca de palavras-chave no acervo de dois destacados veículos noticiosos, durante 0 ano de 2014: o jornal Folha de S. Paulo e o telejornal Jornal Nacional. A aplicação da metodologia da análise de conteúdo tornou possível identificar, a partir do levantamento das matérias, como uma noção de religião de cunho exclusivista é construída a partir do noticiário.

\section{Considerações preliminares: notas sobre o pluralismo religioso no Brasil'}

Quando os portugueses, no século XVI, aportaram e tomaram posse da terra que, mais tarde, se chamou Brasil, uma variedade de formas religiosas já era ali vivenciada por séculos nas mais diferentes tradições. 0 encontro que estes povos tiveram com os colonizadores significou também o encontro com uma cultura e uma religião diferentes: 0 cristianismo e sua expressão do catolicismo ibérico. Com a força da ocupação colonial, o catolicismo romano se fez "a" religião do Continente, tornando as religiões indígenas demonizadas e marginalizadas.

Os encontros religiosos não terminaram com aquela experiência. A chegada dos milhões de negros compulsoriamente trazidos da África para habitar e trabalhar no Novo Mundo promoveu, também, um novo encontro com culturas e com formas religiosas diversas, as quais os escravos procuravam manter vivas. Mais uma vez, 0 catolicismo romano vinculado ao sistema colonial como religião oficial demonizou e marginalizou a religião do Outro. No entanto, os negros escravos encontraram meios de manter vivas suas tradições, adaptando-as à tradição dominante. 0 Brasil começou, então, a experimentar suas primeiras expressões sincréticas de religião.

0 encontro destas distintas tradições religiosas catolicismo ibérico, religiões indígenas e religiões africanas - e as consequentes práticas que ele promoveu, as quais nunca se distanciaram das expressões de vida/cultura, tornaram possível que 0 Brasil se configurasse um país plural. Esta pluralidade é particularmente expressa nas formas religiosas, já que não é possível afirmar que exista uma única expressão seja de catolicismo romano, de religião indígena e de religião de matriz africana.

Este quadro se tornou mais complexo no século XIX, com novos encontros: a chegada das missões protestantes (metodistas, presbiterianas, congregacionais, batistas, episcopais, luteranas), principalmente originárias dos Estados Unidos, mas também da Europa, bem como a vinda de imigrantes da Ásia para substituírem os escravos, após o processo de abolição da escravatura, no trabalho das fazendas.

0 resultado de tal variedade de encontros culturais foi 0 estabelecimento e 0 desenvolvimento de uma multiplicidade de 
expressões religiosas no Brasil, inclusive internamente aos próprios grupos. Neste ponto, é importante recordar que o Pentecostalismo e sua miríade de denominações encontrou solo fértil na América Latina e tornou-se 0 fenômeno religioso mais expressivo do continente desde 0 começo do século XX, quando nele se estabeleceu. 0 crescimento numérico e geográfico dos pentecostalismos no Brasil tem se consolidado com a ampliação da presença destes grupos religiosos nas mídias e na política partidária, e tem potencializado o declínio numérico do catolicismo, até então tido grupo religioso soberano por ser majoritário nestas terras.

De acordo com a pesquisa "Religião na América Latina”, do Pew Research Center (2014), 0 catolicismo é a única denominação cristã que perdeu terreno na região em anos recentes. No entanto, católicos ainda representam mais de dois terços da população adulta em nove dos 18 países latino-americanos e um território estadunidense (Porto Rico) pesquisados: cerca de 425 milhões são católicos, ou 40\% dos fiéis de todo o mundo. Porém, o declínio tende a continuar com o crescimento dos grupos protestantes, particularmente os pentecostais, bem como o aumento dos que se declaram sem religião. 0 movimento carismático presente tanto na Igreja Católica Romana quanto nas Protestantes Históricas tem representado a busca de uma síntese entre a tradição e a religião pentecostal, a fim de promover um reencontro dessas denominações com as camadas populares da população.
No Brasil, fora desta "guerra" no campo cristão, estão as religiões de matriz indígena, africana e asiática, as quais têm menor número de seguidores, mas forte presença sociocultural.

Para finalizar estas considerações preliminares, é possível tomar três afirmações como pontos significativos para o estudo que aqui se apresenta: 1) o Brasil se tornou um país predominantemente cristão sob a força do sistema colonial e 0 apoio da República posteriormente estabelecida; 2) 0 catolicismo tem lutado para manter sua hegemonia no campo religioso, luta que tem sido travada dentro do seu próprio território por séculos, face aos diferentes grupos e movimentos que traz consigo; 3) o movimento Pentecostal é a força religiosa que tem colocado a hegemonia católica sob ameaça.

\section{Considerações teóricas: o conceito de religião dominante}

0 conceito de "religião dominante" ou "religião predominante", próprio do campo das Ciências da Religião, tem embasado múltiplos enfoques que colocam no centro a comunicação em diferentes contextos mundiais. Ele pode ser evocado neste estudo, no que diz respeito à posição do catolicismo romano.

As grandes religiões mundiais e as confissões cristãs majoritárias em distintos lugares do mundo ganham, frequentemente, a classificação de "religião dominante" ou de "grupo dominante". 
Ao tratar do tema em relação ao contexto dos

Estados Unidos da América, Lewis Z. Scholosser

explica a noção desta forma:

Porque a maioria dos americanos são cristãos, 0 cristianismo é a religião dominante nos Estados Unidos. Por causa de sua superioridade numérica e de posições políticas de longa data, os cristãos têm mais poder do que todos os grupos religiosos minoritários combinados. Vários exemplos de manchetes de notícias têm ilustrado esta questão. (...) Como grupo dominante, os cristãos desfrutam de uma variedade de privilégios (...). Um número significativo de pessoas com vinculações religiosas não-cristãs vive e trabalha na sociedade norte-americana $\mathrm{e}$ têm a experiência de ser uma minoria no tocante à sua identificação como grupo religioso. É importante observar, no entanto, que certas denominações do cristianismo (por exemplo, Igreja de Jesus Cristo dos Santos dos Últimos Dias, Adventistas do Sétimo Dia) não parecem gozar dos mesmos privilégios que os seus homólogos de grupos cristãos maiores. Isto porque provavelmente alguns dos maiores grupos cristãos não veem estas denominações menores como cristãs (ou seja, estas denominações são vistas como seitas), mesmo que estas denominações se auto-identifiquem como cristãs. Ademais, estereótipos negativos sobre essas denominações menores contribuem para os membros desses grupos se sentirem como uma minoria oprimida. Sendo uma minoria numérica também se traduz nestas denominações menores o pouco poder na sociedade dos EUA. Apesar destas razões, os membros dessas denominações menores ainda desfrutam de algumas vantagens como membros da religião cristã" (Scholosser, 2003, p. 46-47, tradução nossa).

Esta abordagem encontra ressonância na realidade brasileira à medida que se pode identificar os mesmos aspectos listados que determinam a dominância do cristianismo e, particularmente, do catolicismo romano: superioridade numérica, destacadas posições políticas históricas, privilégios na esfera pública e a classificação de alguns grupos dentro do próprio cristianismo como não cristãos, caso dos pentecostais no país (e no continente latino-americano), até hoje classificados por algumas lideranças católicas-romanas como "seitas". Scholosser destaca o lugar das mídias neste processo, na medida em que manchetes de jornais iluminam a questão, o que será demonstrado adiante.

Se a aplicação do conceito se detiver na concepção de que a dominância do catolicismo no Brasil deve-se somente às questões listadas anteriormente (número, posição política, privilégios e desqualificação de pares), ao se reconhecer o crescimento do Pentecostalismo e a consequente perda de fiéis da Igreja Católica no país, este estudo não poderia tomá-la. Para isso, será necessário relacionar à compreensão de religião dominante duas outras perspectivas: a noção de hegemonia e a dimensão cultural.

A noção de hegemonia, tal como desenvolvida por Antonio Gramsci (2000), tem relação com estratégias de poder que produzem uma visão de mundo e uma aceitação dessa visão. Hegemonia, portanto, produz realidade e produz naturalizações que levam à sua aceitação. 0 sucesso da hegemonia se dá quando a dominância de certas crenças e práticas é tratada como elementos naturais, inquestionáveis, que compõem uma "ordem natural das coisas". 
Daí o lugar de uma religião ser identificado em uma dada sociedade como uma presença natural e óbvia na esfera pública - um lugar garantido, reservado -, ainda que um determinado grupo religioso esteja numericamente abalado, como é 0 caso do catolicismo no Brasil. Mesmo que exista concorrência no campo religioso e haja perdas na posição historicamente assumida, a hegemonia de uma religião se sustenta pelo papel que ela desempenha no processo de construção da realidade, na "ordem natural das coisas".

E neste processo hegemônico, deve-se considerar a perspectiva cultural resultante da construção do imaginário religioso coletivo. Raymond Williams estabelece a relação entre hegemonia e cultura quando indica que o resultado do exercício da hegemonia pode ser identificado em vivências culturais, em "sua aceitação como 'realidade normal' ou 'senso comum' por aqueles que, na prática, lhe são subordinados" (2007, p. 200). Por isso é que não cabe relacionar hegemonia com coerção, pois nela se tem a identificação cultural e 0 consentimento social vinculados a uma gama de convicções, instituições sociais que passam pela moral e pelos costumes (comportamento) e também a rejeição, a abolição e a superação de outras crenças e sentimentos (Gramsci, 2002).

Ou seja, é possível afirmar, neste sentido, que a ideia de "religião dominante", em relação ao catolicismo no Brasil, resulta de uma prática cultural construída a partir do imaginário social de "verdadeira e válida religião". Aqui é que o papel das mídias se torna fundamental, uma vez que este imaginário permeia a formação dos produtores de notícias. Para isso, será importante uma reflexão sobre o processo de construção da notícia.

\section{Considerações teóricas: \\ o processo de construção da notícia}

Distante do que ainda é a compreensão de muitos, a notícia não é o resultado de um trabalho técnico em que o profissional escreve por si só seus textos, mas, sim, de um processo de construção que começa com a compreensão do jornalista da realidade social na qual os eventos acontecem.

Miquel Rodrigo Alsina expõe alguns aspectos importantes desta perspectiva:

A realidade social é resultante de ações sociais intersubjetivas. "A realidade não pode ser completamente diferente do modo como os agentes a interpretam, a internalizam, a reelaboram, e a definem histórica e culturalmente" (Grossi). Construção da realidade, portanto, é produção de sentido através da prática produtiva e das rotinas da organização da profissão jornalística (Alsina, 2005, p. 8).

Este processo está diretamente vinculado ao lugar que a linguagem tem na sociedade. Como expressão da realidade, ela mesma é parte do processo de construção social. Isso significa que o indivíduo, ao nascer, já recebe, no aprendizado da linguagem, os conceitos construídos em sociedade e, a partir deles, elabora as palavras e, por sua vez, os discursos. As teorias do discurso tomam por base esta concepção da linguagem 
como percepção da realidade por meio do estudo da formação discursiva, que implica tanto o que está dito quanto o que não está (os silêncios e os esquecimentos). Alsina trata esta questão quando cita Albert Chillón:

Não existe uma só realidade objetiva externa aos indivíduos, e sim múltiplas realidades subjetivas, inúmeras experiências. E essas múltiplas realidades subjetivas, e que são inevitáveis, adquirem sentido para cada um e se intercomunicam com os outros na medida em que são verbalizadas: enfiadas nas palavras e alicerçadas em anúncios lingüísticos. Os limites do mundo de cada um estão definidos, principalmente, pelos limites da linguagem com a qual e no qual cada um percebe e vive o mundo, o seu mundo (Chillón apud Alsina, 2005, p. 41).

Ao produzir uma notícia, um jornalista traz consigo sua visão de mundo, resultante dos conceitos construídos em sociedade e com os quais interagiu (na família, na escola, nos círculos de convivência). Estes conceitos são criações do imaginário coletivo (Castoriadis, 1995). Ao construir uma notícia, o jornalista tem com ele 0 imaginário em torno da questão que a motiva, do fato que a provoca, do tema que a remete.

No que diz respeito à religião, uma coleção de significações sociais determina 0 conhecimento e a visão de mundo de cada pessoa. Um jornalista, como qualquer outro membro da sociedade, experimenta este processo. Sua compreensão de religião pode ou não ser o resultado de uma experiência religiosa, mas está diretamente ligada à concepção que ele/ela tem de Deus (Badaracco, 2005).

Este estudo sobre a forma como o noticiário sobre religião é veiculado nas principais mídias do Brasil busca mostrar como, no imaginário de seus produtores, Deus é Católico Romano.

\section{Um quadro da religião dominante nas mídias noticiosas}

Para comprovar as premissas que orientam este trabalho, foi realizado um levantamento das matérias que trataram do tema "religião", em duas expressivas mídias noticiosas brasileiras durante 0 ano de 2014: o jornal Folha de $S$. Paulo (Folha) e o telejornal Jornal Nacional (JN). Estes veículos foram selecionados a partir do critério de serem duas mídias diferentes e representativas no que se refere ao maior alcance de público no Brasil².

0 ano de 2014 é significativo para este estudo, pois foi caracterizado por destacados fatos jornalísticos que envolvem religiões, potencializando a avaliação que aqui é proposta:

Dados da Associação Nacional de Jornais (Disponível em http://www.anj.org.br/maiores-jornais-do-brasil/. Acesso em 26 jul 2015) e do IBOPE (Disponível em http://www.ibope.com.br. Acesso em 26 jul 2015). A Folha é o jornal impresso brasileiro com maior tiragem e circulação entre os diários nacionais, com média, em janeiro de 2015, de 365.429 exemplares/dia. Também lidera em edições digitais, com média de 161.200 diárias (janeiro de 2015). 0 JN, da Rede Globo de Televisão, é o telejornal líder de audiência e referência na produção telejornalística do país. Esta liderança e o status de referência predominam até o presente, apesar de uma significativa queda dos índices de audiência, devido às mudanças nos hábitos de consumo da televisão aberta. 
- Em nível global: (1) o surgimento, no Oriente Médio, do grupo político de orientação religiosa, denominada Estado Islâmico, identificado por práticas baseadas em extrema violência; (2) as viagens missionárias do Papa Francisco a países identificados como não cristãos, como Turquia e Coreia do Sul, e também à Terra Santa e os seus desdobramentos políticos; (3) intenso confronto bélico entre Israel e Palestina.

- Em nível nacional: (1) as eleições nacionais no Brasil que, pela primeira vez, contaram com dois candidatos evangélicos à Presidência da República (Marina Silva, pelo Partido Socialista Brasileiro; Pastor Everaldo, pelo Partido Social Cristão), e com dois candidatos evangélicos ao governo do Estado do Rio de Janeiro, Anthony Garotinho e Marcelo Crivella; (2) o processo de canonização, pela Igreja Católica (Vaticano), do padre jesuíta espanhol José de Anchieta, educador e catequista, vindo de Portugal, no século XVI, tendo sido fundador de São Paulo e um dos primeiros autores da literatura brasileira; (3) a fundação, pela Igreja Universal do Reino de Deus, do Templo de Salomão, uma réplica do antigo templo judaico de Jerusalém, que se tornou o maior espaço religioso do país, com o custo de quase 200 milhões de dólares estadunidenses.

Para o levantamento das matérias, foram consultados 0 acervo digital da Folha (verificação em todas as edições impressas de 2014 - as que são vendidas em espaços públicos e são entregues a assinantes) ${ }^{3}$ e 0 acervo de matérias do $J N$, disponível no website Globo.tv . Foram consideradas apenas as matérias identificadas como noticiosas (informativas), tendo sido descartados editoriais, colunas, artigos analíticos, crônicas, sinopses e resenhas. Entre 0 material noticioso, foram selecionadas apenas as matérias em que "religião" era ou fazia parte da temática central, tendo sido desconsiderados os textos que continham apenas uma simples menção de religiões, grupos ou referências religiosas.

Com base no material coletado, foi aplicada a metodologia da análise de conteúdo por meio: (1) da verificação da incidência de palavras-chave relacionadas ao tema "religião"; (2) da análise dos conteúdos verbais do título e dos corpos de textos.

Para verificação de incidência e dos conteúdos verbais, foram utilizadas as seguintes palavraschave: religião, cristianismo, cristão, católico, papa, evangélico, judaísmo, judeu, judaico, islamismo, islã, muçulmano, budismo, buda, dalai lama, candomblé, umbanda, umbandista, espiritismo, espírita, fundamentalismo. 


\subsection{Verificando números: interpretação das incidências}

Para uma interpretação do sentido que as incidências de matérias sobre religião trazem para este estudo, foi estimado um total de 22.000 matérias estritamente noticiosas/informativas publicadas pela Folha (média de 60 matérias, nas 365 edições do ano) e de 6.260 pelo $J N$ (média de 20 matérias nas 313 edições do ano, de segunda a sábado). 0 levantamento mostrou o total de 427 matérias contendo palavras-chave na temática "religião": 312 na Folha e 115 no JN. Os números inexpressivos, quanto ao quadro geral das matérias produzidas, indicam que 0 tema não é uma prioridade nessas mídias, inexistindo uma seção ou editoria específica para cobertura especializada.

A frequência das palavras-chave nas matérias, ou a ausência delas (como no caso de "espiritismo" e "espírita", que não foram encontradas em uma única matéria do $J N$ ), tornou possível um agrupamento de subtemas de religião tratados pelas duas mídias estudadas, em 2014:

- Cristianismo

- Geral

- Católicos

- Evangélicos

- Islamismo

- Judaísmo

- Budismo

- Hinduísmo

- Religióes brasileiras de matriz africana (Candomblé e Umbanda)

- Espiritismo

- Outros (assuntos gerais: ateísmo, liberdade de crença, fé vs. ciência).

Gráfico 1: Matérias noticiosas sobre religião / Folha e JN

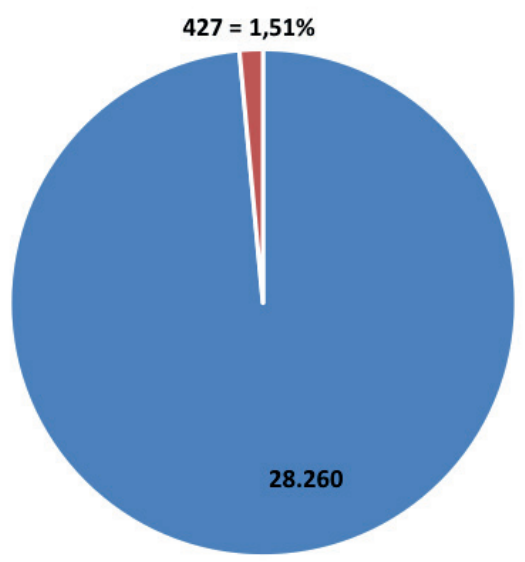




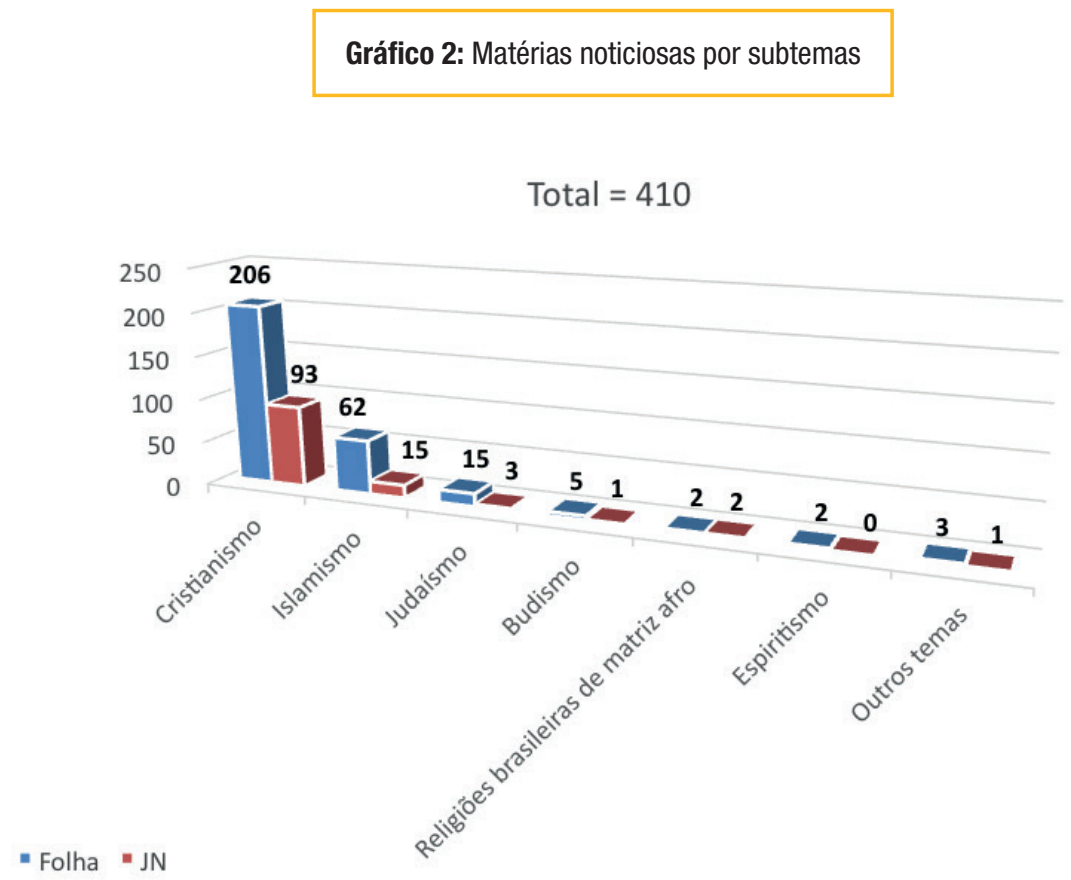

0 gráfico anterior apresenta a incidência de matérias sobre estes subtemas nos dois veículos estudados.

Verifica-se que a maior incidência é a cobertura noticiosa de temas referentes ao cristianismo (73\%), seguida do islamismo (19\%). Fica evidente o predomínio do cristianismo como religião mais valorizada nas notícias, o que corresponde ao fato de 0 Brasil ser um país majoritariamente cristão. Contudo, não é a segunda religião do Brasil o espiritismo, a mais frequentemente representada nas notícias, e, sim, o islamismo. Isso pode ser explicado pelo posicionamento desta última no quadro político global, mas deve-se observar a ampla diferença no número de matérias. As demais religiões ganham abordagem bastante inferior nas duas mídias, em termos numéricos.
Desta forma, os números indicam que, de acordo com o jornalismo praticado nos veículos mais lidos e mais assistidos no Brasil, informação sobre religião é informação sobre 0 cristianismo e quiçá sobre 0 islamismo. Neste quadro, as demais religiões não são passíveis de atenção e valorização, restando-lhes um pequeno espaço no noticiário, quando protagonizam temáticas que alcancem 0 nível de relevância definido por essas mídias.

É importante observar que a referência ao predomínio do cristianismo não revela nível de representação coerente com a diversidade que este grupo apresenta no campo religioso brasileiro. Há uma distinção numérica significativa no tratamento das confissões religiosas incluídas no subtema "cristianismo", com predomínio claro do catolicismo, como se pode verificar no gráfico a seguir. 
Gráfico 3: Matérias noticiosas - subtema Cristianismo

Total: 299

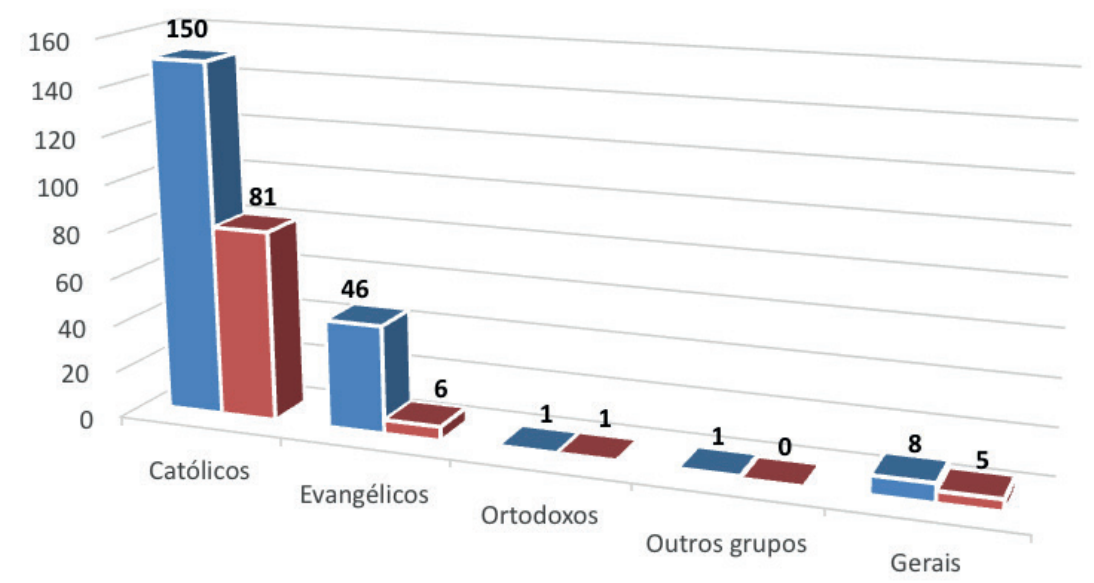

- Folha - JN

Fonte: Elaborado pela autora

A incidência de matérias sobre 0 cristianismo

na Folha e no $J N$ revela um amplo espaço ao

catolicismo: 77,3\% do total das matérias nas duas

mídias, sendo o $J N$ aquele que, proporcionalmente, mais se dedica à temática: $88 \%$ frente a $73 \%$ da

Folha. Os evangélicos aparecem como segundo grupo mais abordado nas matérias sobre religião, no entanto, com uma diferença numérica intensamente inferior: $17,5 \%$ nos dois veículos, sendo a Folha a mídia que mais publicou temas que enfatizaram os evangélicos, proporcionalmente, (22,3\%) frente ao JN (6,5\%). É nítido que outros grupos cristãos foram fortemente desconsiderados no quadro geral das matérias.

A verificação quantitativa das incidências de matérias que tratam "religião" na Folha e no $J N$ confirma uma das premissas assumidas neste trabalho, de que as notícias veiculadas pelas grandes mídias brasileiras cobrem primordialmente 0 cristianismo, especialmente o catolicismo romano institucionalizado. Esta perspectiva silencia notícias sobre outras religiões, bem como aquelas sobre outros cristãos, em especial pentecostais, aqueles em maior evidência no quadro religioso do país.

Esta constatação corrobora a indicação de que este é um caso de comunicação da "religião dominante", correspondendo ao que tratam as abordagens voltadas para esta temática em diferentes continentes. Entretanto, interessa a este estudo demonstrar que a noção de religião dominante não passa somente por dimensões que refletem o lugar de uma religião majoritária em uma dada sociedade, como número de fiéis, posição política 
da instituição religiosa, privilégios daí decorrentes e desqualificação de pares. Levando-se em conta o que já foi indicado anteriormente, referente ao crescimento do pentecostalismo e à consequente perda de fiéis da Igreja Católica, aqui se pretende refletir como a noção de "religião dominante" atribuída ao catolicismo no Brasil permanece viva, porque resulta de uma prática cultural construída a partir do imaginário social de "verdadeira e válida religião". Para isso, é preciso ir além dos números de incidência e verificar como os grupos religiosos são representados por meio dos conteúdos e temáticas veiculados.

\subsection{Verificando conteúdos: categorias para análise}

Os conteúdos verbais (título e corpo das matérias) das matérias coletadas estão agrupados, a seguir, por temas/fatos noticiados e são analisados por meio da categorização das abordagens em duas unidades: (1) abordagens positivas na representação da religião (conteúdo simpático e valorizador, com destaque à harmonia e caráter agregador, educativo, gerador de confiança, de apelo à adesão) - categoria "positiva"; (2) abordagens negativas na representação da religião (conteúdo antipático e desvalorizador, com destaque a conflitos e crises, gerador de desconfiança, de apelo à rejeição) - categoria "negativa". Os resultados são apresentados nos quadros a seguir.

Na visualização das categorizações de valor, é clara a indicação de que a confissão religiosa representada positivamente (100\%) nos veículos noticiosos de maior audiência no Brasil entre jornais impressos e TV (Folha e JN) é o catolicismo. Alcançam 100\% de representação positiva também

Quadro 1: Temas referentes ao Cristianismo Católico Romano

\begin{tabular}{|l|c|c|c|c|}
\hline \multicolumn{1}{|c|}{ Temas referentes ao Cristianismo Católico } & $\begin{array}{c}\text { Matérias } \\
\text { na Folha }\end{array}$ & $\begin{array}{c}\text { Categorização } \\
\text { predominante }\end{array}$ & $\begin{array}{c}\text { Matérias } \\
\text { no JN }\end{array}$ & $\begin{array}{c}\text { Categorização } \\
\text { predominante }\end{array}$ \\
\hline $\begin{array}{l}\text { Papa (declarações, visitas, aumento } \\
\text { de confiança na Igreja Católica, casos curiosos) }\end{array}$ & 59 & Positiva & 50 & Positiva \\
\hline $\begin{array}{l}\text { Sínodo do Vaticano sobre a Família (tratamento } \\
\text { geral do evento - o Papa não é a voz principal) }\end{array}$ & 12 & Positiva & 3 & Positiva \\
\hline Pedofilia e abuso sexual & 15 & Positiva & 6 & Positiva \\
\hline $\begin{array}{l}\text { Temas gerais/curiosidades sobre } \\
\text { a Igreja Católica no Brasil }\end{array}$ & 7 & Positiva & 4 & Positiva \\
\hline Canonização dos Papas João XXIII e João Paulo II & 6 & Positiva & 2 & Positiva \\
\hline $\begin{array}{l}\text { Canonização do Padre José de Anchieta } \\
\text { jesuíta espanhol que atuou no Brasil no século XVI) }\end{array}$ & 5 & Positiva & 4 & Positiva \\
\hline $\begin{array}{l}\text { Banco do Vaticano (reforma, em que } \\
\text { o Papa não é a voz principal) }\end{array}$ & 5 & Positiva & 1 & Positiva \\
\hline Arcebispo do Rio de Janeiro se torna Cardeal & 4 & Positiva & 2 & Positiva \\
\hline Festas religiosas e romarias católicas & Positiva & 7 & Positiva \\
\hline
\end{tabular}




\begin{tabular}{|c|c|c|c|c|}
\hline Turismo religioso (Brasil e Vaticano) & 3 & Positiva & 1 & Positiva \\
\hline Falecimento de lideranças católicas brasileiras & 2 & Positiva & 1 & Positiva \\
\hline $\begin{array}{l}\text { Temas gerais/curiosidades sobre } \\
\text { a Igreja Católica em outros países }\end{array}$ & 6 & Positiva & 0 & \\
\hline Temas gerais/curiosidades sobre o Vaticano & 4 & Positiva & 0 & \\
\hline Igreja Católica e política no Brasil & 4 & Positiva & 0 & \\
\hline Ações sociais solidárias (Brasil e exterior) & 3 & Positiva & 0 & \\
\hline $\begin{array}{l}\text { Casos em torno da representação } \\
\text { da fé católica em produções culturais }\end{array}$ & 3 & Positiva & 0 & \\
\hline $\begin{array}{l}\text { Padre realiza missa pedindo chuva } \\
\text { no interior de São Paulo }\end{array}$ & 2 & Positiva & 0 & \\
\hline $\begin{array}{l}\text { Padre como vítima de racismo } \\
\text { na própria igreja no interior de São Paulo }\end{array}$ & 2 & Positiva & 0 & \\
\hline Excomunhão de padre que defende gays pelo Vaticano & 2 & Positiva & 0 & \\
\hline $\begin{array}{l}\text { Casos de violência (assaltos) envolvendo } \\
\text { lideranças e paróquias no Brasil }\end{array}$ & 2 & Positiva & 0 & \\
\hline
\end{tabular}

\begin{tabular}{|l|c|c|c|c|}
\hline \multicolumn{1}{|c|}{ Temas referentes ao Cristianismo evangélico } & $\begin{array}{c}\text { Matérias } \\
\text { na Folha }\end{array}$ & $\begin{array}{c}\text { Categorização } \\
\text { predominante }\end{array}$ & $\begin{array}{c}\text { Matérias } \\
\text { no JN }\end{array}$ & $\begin{array}{c}\text { Categorização } \\
\text { predominante }\end{array}$ \\
\hline $\begin{array}{l}\text { Evangélicos e Política no Brasil (incluída } \\
\text { uma sobre eleições para o Congresso nos EUA) }\end{array}$ & 17 & Negativa & 4 & Positiva \\
\hline Práticas religiosas peculiares e críticas & 8 & Negativa & 0 & \\
\hline Cultura gospel (entretenimento e mercado religiosos) & 7 & Negativa & 0 & \\
\hline $\begin{array}{l}\text { lgreja Universal do Reino de Deus: } \\
\text { megatemplo e outros casos }\end{array}$ & 4 & Negativa & 0 & \\
\hline Cessão de canais de TV a igrejas evangélicas & 3 & Negativa & 0 & \\
\hline Eventos religiosos & 2 & Negativa & 2 & Positiva \\
\hline Casos de celebridades evangélicas & 2 & Positiva & 0 & \\
\hline Casos policiais & 2 & Negativa & 0 & \\
\hline $\begin{array}{l}\text { Pesquisa Pew - aumentam evangélicos } \\
\text { na América Latina e conservadorismo }\end{array}$ & 1 & Negativa & 0 & \\
\hline
\end{tabular}


Quadro 3: Temas referentes ao Cristianismo Ortodoxo, outros grupos cristãos e cristãos de modo geral

\begin{tabular}{|l|c|c|c|c|}
\hline $\begin{array}{c}\text { Temas referentes ao Cristianismo Ortodoxo, } \\
\text { outros grupos cristãos e cristãos de modo geral }\end{array}$ & $\begin{array}{c}\text { Matérias } \\
\text { na Folha }\end{array}$ & $\begin{array}{c}\text { Categorização } \\
\text { predominante }\end{array}$ & $\begin{array}{c}\text { Matérias } \\
\text { no JN }\end{array}$ & $\begin{array}{c}\text { Categorização } \\
\text { predominante }\end{array}$ \\
\hline Casos gerais & 8 & Negativa & 5 & Positiva \\
\hline Ortodoxos & 1 & Positiva & 1 & Negativa \\
\hline Outros grupos cristãos: Testemunhas de Jeová & 1 & Negativa & 0 & \\
\hline
\end{tabular}

Quadro 4: Temas referentes ao Islamismo

\begin{tabular}{|l|c|c|c|c|}
\hline \multicolumn{1}{|c|}{ Temas referentes ao Islamismo } & $\begin{array}{c}\text { Matérias } \\
\text { na Folha }\end{array}$ & $\begin{array}{c}\text { Categorização } \\
\text { predominante }\end{array}$ & $\begin{array}{c}\text { Matérias } \\
\text { no JN }\end{array}$ & $\begin{array}{c}\text { Categorização } \\
\text { predominante }\end{array}$ \\
\hline Estado Islâmico & 26 & Negativa & 4 & Negativa \\
\hline Opressão das mulheres & 7 & Negativa & 1 & Negativa \\
\hline Atentados, conflitos & 5 & Negativa & 5 & Negativa \\
\hline Política e religião em países identificados como islâmicos & 4 & Negativa & 2 & Negativa \\
\hline Situação dos refugiados do Iraque e da Síria & 4 & Positiva & 0 & \\
\hline $\begin{array}{l}\text { Conservadorismo e intolerância de lideranças políticas } \\
\text { e religiosas em países identificados como islâmicos }\end{array}$ & 4 & Negativa & 0 & \\
\hline Mercado, indústria cultural e grupos islâmicos & 4 & Negativa & 0 & \\
\hline Ações solidárias & 2 & Positiva & 0 & \\
\hline $\begin{array}{l}\text { Ameaças a patrimônios culturais por ações de grupos } \\
\text { radicais }\end{array}$ & 2 & Negativa & 0 & \\
\hline Islamismo na Europa & 2 & Negativa & 3 & \multirow{2}{*}{ Negativa } \\
\hline Peregrinação xiita no Iraque & 1 & Positiva & 0 & \\
\hline Brasileira se converte ao Islamismo e apoia Hamas & 1 & Negativa & 0 & \\
\hline
\end{tabular}




\begin{tabular}{|l|c|c|c|c|}
\hline \multicolumn{2}{|c|}{ Quadro 5: Temas referentes ao Judaísmo } \\
\multicolumn{1}{|c|}{ Temas referentes ao Judaísmo } & $\begin{array}{c}\text { Matérias } \\
\text { na Folha }\end{array}$ & $\begin{array}{c}\text { Categorização } \\
\text { predominante }\end{array}$ & $\begin{array}{c}\text { Matérias } \\
\text { no JN }\end{array}$ & $\begin{array}{c}\text { Categorização } \\
\text { predominante }\end{array}$ \\
\hline Judaísmo no Brasil & 2 & Positiva & 0 & \\
\hline Judaísmo em outros países (não Israel) & 7 & Positiva & 0 & \\
\hline Judaísmo em Israel & 3 & Negativa & 0 & \\
\hline Conflitos praticados ou sofridos por judeus & 3 & Negativa & 3 & Positiva \\
\hline
\end{tabular}

Quadro 6: Temas referentes a outros grupos ou temas religiosos

\begin{tabular}{|l|c|c|c|c|}
\hline \multicolumn{1}{|c|}{$\begin{array}{c}\text { Temas referentes a outros grupos } \\
\text { ou temas religiosos }\end{array}$} & $\begin{array}{c}\text { Matérias } \\
\text { na Folha }\end{array}$ & $\begin{array}{c}\text { Categorização } \\
\text { predominante }\end{array}$ & $\begin{array}{c}\text { Matérias } \\
\text { no JN }\end{array}$ & $\begin{array}{c}\text { Categorização } \\
\text { predominante }\end{array}$ \\
\hline Budismo & 5 & Positiva & 1 & Positiva \\
\hline Hinduísmo & 3 & Negativa & 1 & Negativa \\
\hline $\begin{array}{l}\text { Outros (assuntos gerais: ateísmo, } \\
\text { liberdade de crença, fé vs. Ciência) }\end{array}$ & 3 & Negativa & 1 & Negativa \\
\hline Religiões brasileiras de matriz africana & 2 & Positiva & 2 & Positiva \\
\hline Espiritismo & 2 & Positiva & 0 & \\
\hline
\end{tabular}

Fonte: Elaborado pela autora

Quadro 7: Síntese da valoração das categorias

\begin{tabular}{|l|c|c|c|c|}
\hline \multicolumn{1}{|c|}{$\begin{array}{c}\text { Grupo Religioso } \\
\text { (número total de temas que o representam) }\end{array}$} & $\begin{array}{c}\text { Categorização } \\
\text { positiva }\end{array}$ & $\%$ & $\begin{array}{c}\text { Categorização } \\
\text { negativa }\end{array}$ & $\%$ \\
\hline Cristianismo Católico (33) & 33 & 100 & 0 & 0 \\
\hline Cristianismo Evangélico (11) & 3 & 27,3 & 8 & 72,7 \\
\hline Outros cristãos (5) & 2 & 40 & 3 & 60 \\
\hline Islamismo (17) & 3 & 17,7 & 14 & 82,3 \\
\hline Judaísmo (6) & 4 & 66,6 & 2 & 33,4 \\
\hline Budismo (6) & 4 & 66,6 & 2 & 33,4 \\
\hline Hinduísmo (4) & 0 & 0 & 4 & 100 \\
\hline
\end{tabular}




\begin{tabular}{|l|c|c|c|c|}
\hline Religiões brasileiras de matriz africana (4) & 4 & 100 & 0 & 0 \\
\hline Espiritismo (2) & 2 & 100 & 0 & \\
\hline Outros (4) & 0 & 0 & 4 & 100 \\
\hline
\end{tabular}

as religiões de matriz africana e o espiritismo, porém, a desconsideração a esses grupos revelada no insignificante número de matérias é muito expressiva. Essas religiões foram abordadas em apenas seis textos de um universo de 425, ou seja, a insignificante marca de 1,51\%, que nem tornou possível, na pesquisa, a realização de um agrupamento temático, como ocorreu em relação aos grupos representados com maior incidência.

0 segundo grupo com mais representação positiva é o judaísmo: $66,6 \%$ das temáticas que 0 abordaram ofereceram tratamento positivo. No entanto, a diferença entre a incidência de temas relacionados ao judaísmo e ao catolicismo é muito grande: quatro para o primeiro contra 33 para 0 segundo, o que revela que a atenção dada pelo noticiário à confissão judaica é bastante restrita.

A representação do islamismo, a segunda em número de matérias e temas, é intensamente negativa, não apenas por conta da emergência de um grupo político insurgente, o Estado Islâmico, e suas práticas de terror e barbárie (maior número de matérias), mas pela tendência que permeia 0 século XXI, de demonização deste grupo religioso que seria uma "ameaça" ao planeta. Isso está nitidamente expresso no tratamento negativo dos conteúdos do noticiário no Brasil, que enfatiza opressão de grupos, atentados, conflitos, intolerância da parte de lideranças. Mesmo temas despolitizados, como um desfile de moda islâmica, tratado em duas matérias, refletem a negação do islamismo pelo noticiário brasileiro, com textos marcados por abordagens que tratam 0 assunto de forma folclórica, pitoresca ${ }^{5}$.

0 mesmo sentido de desqualificação pode ser observado na representação dos evangélicos, pelo amplo número de pautas negativas. É 0 segundo grupo religioso mais representado em matérias sobre o cristianismo. Dos nove temas agrupados, apenas um teve representação positiva - o que trata de eventos religiosos, mais especificamente, de uma grande manifestação de rua realizada anualmente, a Marcha para Jesus. Todo o conteúdo das demais matérias apresenta os evangélicos, suas práticas religiosas e expressões culturais, de modo pejorativo, com textos marcados por ironia e termos que revelam 
desconfiança. Em ascensão numérica e geográfica

no Brasil e na América Latina, com forte presença, especialmente do segmento pentecostal, nas

mídias e na política partidária, o cristianismo evangélico tem sido interpretado em várias esferas como uma "ameaça" ao catolicismo, responsável pela intensificação do declínio no número de fiéis da Igreja Católica no continente. Isso parece ser assumido pelas mídias noticiosas.

No caso específico do $J N$, apesar de dedicar um tratamento positivo à maior parte de suas matérias sobre os evangélicos, os números mostram que este grupo não tem espaço ou não merece destaque no seu noticiário: apenas seis matérias frente às 81 sobre 0 catolicismo e às 115 do total sobre religião.

Como a análise de conteúdo da cobertura sobre religião nos veículos noticiosos Folha e $J N$ demonstra, produtores de notícias veem e apresentam 0 Brasil como um país quase que totalmente católico-romano. 0 título de uma matéria sobre as eleições no Brasil, publicada na Folha, em 15 de setembro de 2014, ilustra como a mídia noticiosa reconstrói o imaginário que trata 0 catolicismo como religião dominante: "Mais tolerante, igreja cobra compromissos de candidatos" Católica. Este conteúdo silencia de forma efetiva todas as outras igrejas cristãs presentes no país e que, certamente, também tinham algo a dizer sobre 0 processo eleitoral. As duas personagens ouvidas pela reportagem são cardeais e falam pela Confederação Nacional de Bispos do Brasil, da Igreja Católica.

Segue na mesma perspectiva matéria do $J N$ (12/4/2014) agrupada na categoria "representação de cristãos de modo geral", em que é apresentada uma diferente tradição de celebração da Páscoa cristã em uma cidade do sul do Brasil, Pomerode $(\mathrm{SC})^{7}$. A abordagem se refere à tradição de imigrantes alemães, vinculados à fé evangélica luterana, mas isso não é mencionado uma vez sequer na longa matéria de mais de dois minutos. Autoridades religiosas não são ouvidas, apenas fiéis e moradores da cidade. Fica para os telespectadores que desconhecem o contexto da imigração luterana no sul do Brasil a simpática mensagem sobre uma prática cristã e, uma vez que as mídias reforçam a noção de que "a" Igreja do país é a Católica, a dedução de que é uma tradição relacionada a essa confissão cristã.

Chama a atenção o destaque dado pelas mídias noticiosas à religião institucionalizada. 0 catolicismo enfatizado é o institucional, presente em $75 \%$ das matérias veiculadas sobre este grupo religioso. As autoridades religiosas católicas são as personagens que têm mais visibilidade 
no noticiário, sendo a mais destacada o Papa, figura central em quase 50\% das matérias sobre o catolicismo e em $25 \%$ do total de notícias sobre religião, seguido de arcebispos, bispos, padres.

0 mesmo não ocorre com os outros grupos religiosos, como, por exemplo, os evangélicos. Nas 52 matérias da Folha e do $J N$ referentes a este grupo, $85 \%$ dão voz a fiéis, celebridades deste grupo religioso, pesquisadores e autoridades públicas não religiosas. Apenas 15\% das notícias destacam autoridades do segmento, ainda assim, algumas delas não são devidamente identificadas ou a instituição a que estão vinculadas não é registrada.

Uma das matérias da Folha sob o título "Igrejas saem às ruas de Kiev para defender o diálogo" $(28 / 1 / 2014)^{8}$ pode ser tomada como ilustrativa desta perspectiva. Não há registro no texto de quais são as igrejas que saem às ruas, mas a principal personagem ouvida pela reportagem é um arcebispo da igreja greco-católica ucraniana, introduzida no texto como "de rito bizantino, mas subordinada à Santa Sé”. Garante-se a fala de uma autoridade vinculada a uma igreja da qual se sabe pouco, mas que, de acordo com o jornalista que produziu a matéria (um brasileiro, enviado especial a Kiev) e o editor que a aprovou, revelase credenciada por ser "subordinada à Santa Sé". A partícula "mas" resume o imaginário dos produtores: um grupo desconhecido que, contudo, pode ser ouvido pelo simples fato de estar sob o controle da hierarquia do catolicismo. A segunda personagem mencionada na matéria não tem nome e é identificada como "um padre evangélico que caminhava pela praça". "Padre evangélico" é um tratamento equivocado pois, na tradição do segmento evangélico, a liderança paroquial é denominada "Pastor" ou "Pastora", diferentemente da Igreja Católica, que a designa "Padre". 0 texto transparece que, no imaginário dos responsáveis pela notícia, a designação de uma liderança religiosa só pode ser aquela do catolicismo.

A referência mais ampla às autoridades católicas e à religião institucionalizada leva ainda à negação da pluralidade que existe dentro do próprio catolicismo, como as diversas práticas de religiosidade popular e as tendências teológicas distintas. No noticiário levantado, a religiosidade popular fica restrita às romarias e festas oficialmente reconhecidas, enquanto a diversidade de tendências teológicas inexiste.

Com base nestas análises temáticas, é possível interpretar que a ideia de "religião dominante", relacionada ao catolicismo no Brasil como "verdadeira e válida religião", está presente na forma como esta expressão religiosa é representada nas mídias noticiosas: predominantemente positiva (conteúdos simpáticos e valorizadores, com destaque à 
harmonia e ao caráter agregador, educativos, geradores de confiança, de apelo à adesão) e credenciada por meio da ênfase na forte presença institucional.

\section{Vozes reduzidas, silêncio ampliado}

Como as mídias noticiosas constroem a imagem de "verdadeira e válida religião" referente ao catolicismo? Levantamos nesta pesquisa evidências de que os produtores de notícias trabalham a partir de um imaginário que remonta à época do Brasil colônia de Portugal, catequisado pelos missionários católicos. Naquela concepção que ainda prevalece, estas terras foram escolhidas por Deus para se tornarem cristãs, uma fé que deve permanecer exaltada. É desse modo que o catolicismo instituído pelos colonizadores como "a" religião, aquela que salvou o Brasil do paganismo, conserva-se arraigado na imaginação social de editores e jornalistas, ainda que tenham conhecimento de que outras expressões religiosas têm lugar significativo ao longo da história do país. Daí o noticiário contribuir para a reconstrução desse imaginário e dessa realidade religiosa.

Importa ressaltar, como referido, que a forte ênfase no catolicismo institucionalizado e em suas autoridades nas matérias noticiosas reforça a dimensão de a Igreja Católica ser "a" Igreja. Transmite-se, com este conteúdo, que institucionalidade e autoridades são o que confere solidez, seriedade e crédito a um grupo religioso.
Nas notícias sobre os demais grupos predominam vozes de fiéis, celebridades e pessoas até mesmo não vinculadas a eles e que se manifestam sobre os temas. Constrói-se assim a imagem de que expressões religiosas não católicas carecem de base institucional, controle da parte de autoridades, solidez, seriedade e crédito.

Por conseguinte, apesar do fato de o domínio numérico católico-romano ter sido colocado em xeque na América Latina, a partir da segunda metade do século XX, por conta do crescimento das igrejas do ramo pentecostal, as mídias noticiosas reconstroem a imagem católica de "religião dominante", aquela que é verdadeira e válida. As notícias publicadas privilegiam o status desse grupo religioso por meio da quantidade de textos e da qualidade dos conteúdos, garantindolhe hegemonia. Nesta dinâmica, o jornalismo praticado silencia sobre fatos que envolvem outras expressões religiosas, ou trata-os de forma pejorativa, negando o quadro complexo da diversidade religiosa no Brasil, inclusive dentro do próprio catolicismo.

Por isso, é possível afirmar que a noção de "religião dominante", construída pelos profissionais que produzem o noticiário no Brasil, configura-se uma concepção exclusivista do cristianismo como sinônimo de catolicismo. Ela reflete 0 imaginário social sobre religião formado ao longo dos séculos de dominação colonial no continente latino-americano. Por meio 
de silêncios e depreciações, esta construção da noção de religião pelo jornalismo nega o lugar e 0 valor do pluralismo e torna-se uma contribuição para posturas de intolerância. Uma vez que informação é "forma que forma... liga, une, junta, a fim de estabelecer comunhão e partilha de algo entre indivíduos e grupos" (MAFFESOLI, 2003, p. 14-15), este tipo de cobertura noticiosa termina por seguir em direção contrária: promove desinformação (desagregação).

É assim que as mídias noticiosas contribuem para que Deus, já tomado nas expressões culturais populares do país como "brasileiro", seja também confessado "católico-romano" e demonize todos os outros.

\section{Referências}

ALSINA, Miquel Rodrigo. A construção da notícia. Petrópolis: Vozes, 2009.

BADARACC0, Claire H. (Ed). Quoting God. How media shape ideas about religion and culture. Texas: Baylor University Press, 2005.

CASTORIADIS, Cornelius. A instituição imaginária da sociedade, $3^{\mathrm{a}}$ ed. Rio de Janeiro: Paz e Terra, 1995.

CUNHA, Magali do Nascimento. A Explosão Gospel. Um olhar das ciências humanas sobre o cenário evangélico contemporâneo. Rio de Janeiro: Mauad, 2004.

GRAMSCI, Antonio. Cadernos do cárcere - Literatura. Folclore. Gramática. Apêndices: variantes e índices. v. 6 . Rio de Janeiro: Civilização Brasileira, 2002.

MAFFESOLI, Michel. A comunicação sem fim (teoria pós-moderna da comunicação). Famecos, Porto Alegre, n. 20, p. 13-20, abr 2003.
PEW RESEARCH CENTER. Religion in Latin America. Religion in Latin America, 13 nov 2014. Disponível em: http://www.pewforum.org/2014/11/13/religion-inlatin-america/. Acesso em 20 set 2015.

SCHLOSSER, Lewis Z. Christian privilege:

Breaking a sacred taboo. Journal of Multicultural

Counseling and Development, 31 (1): 44-51, jan

2003. Disponível em: https://wiki.uiowa.edu/download/ attachments/39006632/Christian + Privilege.pdf. Acesso em 20 set 2015 .

WILLIAMS, Raymond. Palavras-chave: um vocabulário de cultura e sociedade. São Paulo: Boitempo, 2007. 


\begin{tabular}{|c|c|}
\hline $\begin{array}{l}\text { Religion in the news: marks } \\
\text { of an exclusivist imaginary } \\
\text { in Brazilian journalism }\end{array}$ & $\begin{array}{l}\text { Religión en las noticias: las marcas } \\
\text { de um imaginario exclusivista en el } \\
\text { periodismo brasileño }\end{array}$ \\
\hline $\begin{array}{l}\text { Abstract } \\
\text { This text aims to evaluate how the different religious } \\
\text { groups are represented in the news media in Brazil } \\
\text { and the understanding of religion built and affirmed } \\
\text { by the producers of this news. The study was guided } \\
\text { by the hypothesis that the news highlights the } \\
\text { institutionalized Roman Catholicism, fueled by the } \\
\text { social imaginary of "true and valid religion." Through } \\
\text { a content analysis it was possible to identify, from } \\
\text { a survey of materials that dealt with the theme } \\
\text { "Religion" during the year 2014, in the collection } \\
\text { of Folha de S. Paulo and Jornal Nacional, how an } \\
\text { exclusivist notion of religion is built in the country } \\
\text { from the news. } \\
\text { Keywords } \\
\text { News. Religion. Imaginary }\end{array}$ & $\begin{array}{l}\text { Resumen } \\
\text { Este texto tiene por objeto evaluar como están } \\
\text { representados los diferentes grupos religiosos em los } \\
\text { médios noticiosos en Brasil y la comprensión de la } \\
\text { religión construido y afirmada por los productores } \\
\text { de esta noticias. El estudio se basó en el hipotésis } \\
\text { de que las noticias destacan el catolicismo romano } \\
\text { institucionalizado, alimentadas por el imaginario } \\
\text { social de "la religión verdadera y válida". A través } \\
\text { de un análisis de contenido fueron identificados a } \\
\text { partir de um estudio de materiales que tratan con el } \\
\text { tema "Religión" durante el año 2014, en la colección } \\
\text { de la Folha de S. Paulo y del Jornal Nacional, como } \\
\text { una noción exclusivista de religión se construye en e } \\
\text { país por las noticias. } \\
\text { Palabras clave }\end{array}$ \\
\hline
\end{tabular}




\section{Expediente}

A revista E-Compós é a publicação científica em formato eletrônico da Associação Nacional dos Programas de Pós-Graduação em Comunicação (Compós). Lançada em 2004, tem como principal finalidade difundir a produção acadêmica de pesquisadores da área de Comunicação, inseridos em instituições do Brasil e do exterior.

\section{E-COMPÓS I www.e-compos.org.br I E-ISSN 1808-2599}

Revista da Associação Nacional dos Programas de Pós-Graduação em Comunicação.

Brasília, v.19, n.1, jan./abr. 2016.

A identificação das edições, a partir de 2008, passa a ser volume anual com três números.

Indexada por Latindex I www.latindex.unam.mx

\section{CONSELHO EDITORIAL}

Alexandre Farbiarz, Universidade Federal Fluminense, Brasil Alexandre Rocha da Silva, Universidade Federal do Rio Grande do Sul, Brasil Ana Carolina Damboriarena Escosteguy, Pontifícia Universidade Católica do Rio Grande do Sul, Brasil

Ana Carolina Rocha Pessôa Temer, Universidade Federal de Goiás, Brasil Ana Regina Barros Rego Leal, Universidade Federal do Piaú, Brasil Andrea França, Pontifícia Universidade Católica do Rio de Janeiro, Brasil André Luiz Martins Lemos, Universidade Federal da Bahia, Brasil Antonio Carlos Hohlfeldt, Pontifícia Universidade Católica do Rio Grande do Sul, Brasil

Arthur Ituassu, Pontifícia Universidade Católica do Rio de Janeiro, Brasil Álvaro Larangeira, Universidade Tuiuti do Paraná, Brasil

Ângela Freire Prysthon, Universidade Federal de Pernambuco, Brasil César Geraldo Guimarães, Universidade Federal de Minas Gerais, Brasil Cláudio Novaes Pinto Coelho, Faculdade Cásper Líbero, Brasil Daisi Irmgard Vogel, Universidade Federal de Santa Catarina, Brasil Denize Correa Araujo, Universidade Tuiuti do Paraná, Brasil Eduardo Antonio de Jesus, Pontifícia Universidade Católica de Minas Gerais, Brasil

Daniela Zanetti, Universidade Federal do Espirito Santo, Brasil Eduardo Vicente, Universidade de São Paulo, Brasil Elizabeth Moraes Gonçalves, Universidade Metodista de São Paulo, Brasil Erick Felinto de Oliveira, Universidade do Estado do Rio de Janeiro, Brasil Francisco Elinaldo Teixeira, Universidade Estadual de Campinas, Brasil Francisco Paulo Jamil Almeida Marques, Universidade Federal do Paraná, Brasil

Gabriela Reinaldo, Universidade Federal do Ceará, Brasil Goiamérico Felício Carneiro Santos, Universidade Federal de Goiás, Brasil Gustavo Daudt Fischer, Universidade do Vale do Rio dos Sinos, Brasil Herom Vargas, Universidade Municipal de São Caetano do Sul, Brasil Itania Maria Mota Gomes, Universidade Federal da Bahia, Brasil
Janice Caiafa, Universidade Federal do Rio de Janeiro, Brasil Jiani Adriana Bonin, Universidade do Vale do Rio dos Sinos, Brasil José Afonso da Silva Junior, Universidade Federal de Pernambuco, Brasil José Luiz Aidar Prado, Pontifícia Universidade Católica de São Paulo, Brasil Juçara Gorski Brittes, Universidade Federal de Ouro Preto, Brasil Kati Caetano, Universidade Tuiuti do Paraná, Brasil Lilian Cristina Monteiro França, Universidade Federal de Sergipe, Brasil Liziane Soares Guazina, Universidade de Brasilia, Brasil Luíza Mônica Assis da Silva, Universidade de Caxias do Sul, Brasil Luciana Miranda Costa, Universidade Federal do Pará, Brasil Malena Segura Contrera, Universidade Paulista, Brasil Maria Ogécia Drigo, Universidade de Sorocaba, Brasil Maria Ataide Malcher, Universidade Federal do Pará, Brasil Marcia Tondato, Escola Superior de Propaganda e Marketing, Brasil Marcel Vieira Barreto Silva, Universidade Federal da Paraíba, Brasil Maria Clotilde Perez Rodrigues, Universidade de São Paulo, Brasil Maria das Graças Pinto Coelho, Universidade Federal do Rio Grande do Norte, Brasil

Mauricio Ribeiro da Silva, Universidade Paulista, Brasil

Mauro de Souza Ventura, Universidade Estadual Paulista, Brasil Márcio Souza Gonçalves, Universidade do Estado do Rio de Janeiro, Brasil Micael Maiolino Herschmann, Universidade Federal do Rio de Janeiro, Brasil Mirna Feitoza Pereira, Universidade Federal do Amazonas, Brasil Nísia Martins Rosario, Universidade Federal do Rio Grande do Sul, Brasil Potiguara Mendes Silveira Jr, Universidade Federal de Juiz de Fora, Brasil Regiane Regina Ribeiro, Universidade Federal do Paraná, Brasil Rogério Ferraraz, Universidade Anhembi Morumbi, Brasil Rose Melo Rocha, Escola Superior de Propaganda e Marketing, Brasil Rozinaldo Antonio Miani, Universidade Estadual de Londrina, Brasil Sérgio Luiz Gadini, Universidade Estadual de Ponta Grossa, Brasil Simone Maria Andrade Pereira de Sá, Universidade Federal Fluminense, Brasil Veneza Mayora Ronsini, Universidade Federal de Santa Maria, Brasil Walmir Albuquerque Barbosa, Universidade Federal do Amazonas, Brasil

\section{COMISSÃO EDITORIAL}

Cristiane Freitas Gutfreind, Pontifícia Universidade Católica do Rio Grande do Sul, Brasil Irene Machado, Universidade de São Paulo, Brasil

Eduardo Antonio de Jesus, Universidade Católica de Minas Gerais, Brasil

\section{CONSULTORES AD HOC}

Cleusa M. Andrade Scroferneker, Pontifícia Universidade Católica do Rio Grande do Sul, Brasil Francisco Rüdiger, Pontifícia Universidade Católica do Rio Grande do Sul, Brasil Juliana Freire Gutmann, Universidade Federal da Bahia, Brasil Karla Regina M. P. Patriota Bronsztein, Universidade Federal de Pernambuco, Brasil Laura Loguercio Cánepa, Universidade Anhembi Morumbi, Brasil Lucia Isaltina C. Leão, Pontifícia Universidade Católica de São Paulo, Brasil

\section{EQUIPE TÉCNICA}

\section{ASSISTENTE EDITORIAL I Márcio Zanetti Negrini}

REVISÃO DE TEXTOS I Press Revisão

EDITORAÇÃO ELETRÔNICA I Roka Estúdio

CONTATO I revistaecompos@gmail.com
COMPÓS I www.compos.org.br

Associação Nacional dos Programas de Pós-Graduação em Comunicação

Presidente

Edson Fernando Dalmonte

Programa de Pós-Graduação em Comunicação

e Cultura Contemporânea - UFBA

edsondalmonte@uol.com.br

Vice-presidente

Cristiane Freitas Gutfreind

Programa de Pós-Graduação em Comunicação Social - PUC-RS cristianefreitas@pucrs.br

Secretário-Geral

Rogério Ferraraz

Programa de Pós-Graduação em Comunicação

Universidade Anhembi Morumbi

rogerioferraraz@anhembimorumbi.edu.br 